\title{
Review
}

\section{Megacolon in patients with chronic spinal cord injury}

\author{
D Harari*,1 and KL Minaker ${ }^{2}$ \\ ${ }^{1}$ Department of Health Care of the Elderly, Guy's, King's, St. Thomas' School of Medicine, St. Thomas' Hospital, \\ London, UK, '2Massachusetts General Hospital Geriatric Medicine Unit, Massachusetts General Hospital/Beacon Hill \\ Senior Health, Boston, Massachusetts, USA
}

Purpose: To investigate the clinical and functional correlates of megacolon in individuals
with chronic spinal cord injury (SCI).
Patients and methods: This is a cross-sectional study of 128 patients consecutively admitted
to a SCI in-patient service in a US Veterans Administration Medical Centre (mean age $57 \pm 15$
years, mean years since injury $20 \pm 13,97 \%$ male) who underwent plain abdominal
radiography for study purposes. Participants were characterised by radiological findings.
'Megacolon' was defined as colonic dilatation of $>6 \mathrm{cms}$ in one or more colonic segment(s).
Clinical, functional, and medication data were abstracted from the medical and nursing
records. Individual interviews were conducted with study participants regarding bowel-related
symptoms and treatment over the previous 1 -month period. Results: Seventy-three per cent of subjects $(n=94)$ had megacolon, and $52 \%$ of these individuals had associated radiological constipation. Subjects with megacolon were compared with those without colonic dilatation $(n=34)$. Factors significantly associated with megacolon were older age, longer duration of injury, symptom of abdominal distension, radiological constipation, urinary outlet surgery, laxative use at least once weekly, use of anticholinergic drugs, and use of calcium-containing antacids. These factors were simultaneously included in a multiple logistic regression model. Independent correlates of megacolon were more than 10 years elapsed since acute injury, age over 50 years, and use of $\geqslant 4$ laxative doses per month. Conclusion: Megacolon is a highly prevalent disorder in individuals with chronic spinal cord injury. Our findings suggest that the presence of megacolon may be predicted in older individuals, and in those who are more than 10 years post-SCI. We also found that clinical constipation was frequently present in individuals with megacolon, despite their significantly greater use of laxatives.

Sponsorship: This work was supported by a grant from the Claude D Pepper Geriatric Research and Training Center from the National Institute of Ageing-AG08812-05, and a grant from the Education and Training Foundation of the Paralyzed Veterans Association in the USA. Dr Harari is currently recipient of a grant from Action Research (UK).

Spinal Cord (2000) 38, 331-339

Keywords: spinal cord injury; megacolon; constipation; abdominal radiograph; age; laxatives

\section{Introduction}

Individuals with chronic SCI suffer from increasingly frequent and severe constipation-related problems as they grow older with their disability. ${ }^{1-3}$ Distressing symptoms such as prolonged and difficult evacuation, recurrent abdominal distension and abdominal pain tend to develop 5 or more years post-injury. ${ }^{1,2}$ Conventional treatments for constipation become less effective, and as the use of laxatives and suppositories increases, so does

*Correspondence: D Harari, Department of Health Care to the Elderly, Guy's, King's, St. Thomas' School of Medicine, St. Thomas' Hospital, Lambeth Palace Road, London SE1, UK. the incidence of faecal impaction. ${ }^{1,2,4,5}$ Acquired megacolon has been postulated as a possible underlying cause of these deteriorating gastrointestinal symptoms in patients with long-standing SCI. The fact that constipation-related disease is uncommon in the first 5 years after injury, would support the hypothesis that the underlying problem is acquired, possibly through degeneration or decompensation of smooth muscle in the gut. ${ }^{2,4}$ In the clinical arena, SCI physicians have observed that in both asymptomatic patients, and in those with bowel-related problems, the plain abdominal radiograph (AXR) often demonstrates dilated gas-filled loops of colon suggestive 
of megacolon. ${ }^{4-6}$ There are however no published data examining the prevalence of megacolon in this population.

Recent consideration has been given to identifying risk factors for the gastrointestinal problems seen in chronic SCI. ${ }^{1,2}$ In a previous publication, we identified tetraplegia, Frankel grade A or $\mathrm{B}^{7}$ increased laxative use, and community-living (as compared with longterm care residency) as factors independently associated with difficulty with evacuation. ${ }^{1}$ The goal of the current study is to examine clinical, functional and pharmacological correlates of megacolon in individuals with chronic SCI, with the overall objective of exploring methods for preventing the problem. A further aim is to describe radiological constipation and other characteristics seen on routine abdominal radiography in SCI patients.

\section{Methods}

\section{Subjects and setting}

All patients consecutively admitted to the SCI service at a US Veterans Administration Medical Centre (VAMC) between April 1993 and January 1994, who were at least 3 months beyond acute injury, were approached for participation. Of the 197 enrollees, 134 patients were examined by plain abdominal radiograph (AXR) within $48 \mathrm{~h}$ of being interviewed regarding bowel-related symptoms. The technical quality of the AXR in six of these cases was insufficient for accurate radiological interpretation. The study population consisted of the remaining 128 patients. Of these, 93 $(73 \%)$ were admitted to the SCI service from the community for a routine annual check-up, 18 (14\%) were admitted as a result of acute medical or surgical illness, and $17(13 \%)$ were residents in a long-term care institution affiliated with the VAMC.

\section{Data collection}

Plain abdominal radiograph The abdominal radiograph was interpreted by an experienced radiologist who was blinded to subject name and other identifying features. The maximum diameter of the ascending, transverse, descending and sigmoid colon and rectum were recorded. The AXR was assessed for constipation according to the following validated method. ${ }^{8}$ Four separate lines were drawn from the center of the L4 vertebra to the tips of the 12th ribs superiorly, and to the widest part of the pelvic brim inferiorly, so dividing the lower gut into four segments (see Figure 1). A scoring system was applied to the ascending colon, transverse colon, descending and sigmoid colon, and rectum as follows: $0=$ no stool, $1=$ small amount of stool, $2=$ moderate stool retention and $3=$ severe stool retention. The 4-line method guided interpretation, but where relevant the radiologist also took into account the presence of redundant colon (usually sigmoid)

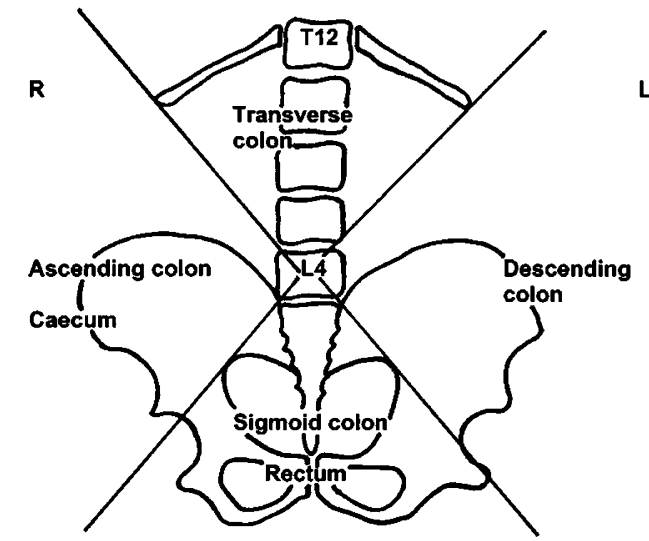

Visualise 4 lines from the center of the L4 vertebra, to the tips of the 12th ribs, and to the widest point of the internal pelvic rim to identify the segments of the large bowel.

Constipation scoring system:

In each of 4 segments (ascending colon, transverse colon, descending/sigmoid colon, and rectum)

$0=$ no stool $1=$ small amount $2=$ moderate stool $3=$ severe stool retention

Radiological Constipation: Total score $>8$

Colonic dilatation: Maximum diameter of colon $>6 \mathrm{cms}$

Rectal dilatation: Maximum diameter of rectum $>4 \mathrm{cms}$

Figure 1 Abdominal radiograph interpretation

overlying another designated segment. Small bowel dilatation was also documented.

Patient interview and chart abstraction All patients were interviewed regarding bowel-related symptoms over the previous 1-month period; the 16-point questionnaire has been detailed in a previous publication. ${ }^{1}$

The medical charts were abstracted for the following information: all medications prescribed over the preceding month, age, sex, reason for admission, date of SCI, highest level of neurological injury, Frankel classification of neurological function below the level of injury, ${ }^{7}$ previous urinary outlet surgery, and diagnosis of diabetes mellitus.

\section{Study definitions}

According to textbook definition, 'megacolon' was defined as maximum colonic diameter greater than $6 \mathrm{cms},{ }^{9}$ and 'megarectum' as rectal diameter $\geqslant 4 \mathrm{cms}$. 'Radiological constipation' was defined as a total stool retention score of $\geqslant 8$, and 'severe faecal retention' as a score of 3 in any segment of the lower bowel (see Figure 1).

\section{Data analysis}

Intraobserver variation was assessed by having the same radiologist reinterpret 19 of the abdominal radiographs 3 months after the initial readings. The kappa statistic was used to measure concordance between the two separate readings. Pearsons rank correlation was used to compare the total faecal retention scores. Patients were classified as having 
'megacolon' or 'no megacolon', and relative risk calculations were used to examine differences between the two groups. Potential risk factors for megacolon were selected for multiple logistic regression analysis based on univariate associations (where the 95\% Confidence Interval of the relative risk does not contain unity). All tests of significance were two-tailed.

\section{Results}

\section{Reliability of $A X R$ interpretation}

In assessing intraobserver variation, the concordance (beyond that expected by chance) between the two readings was high, with a kappa score of 0.81 for megacolon. The kappa score for severe faecal retention in the four colonic segments ranged between 0.87 and 1.0 (the latter value referring to the ascending colon). The squared correlation coefficient for the total stool retention score was 0.96 , indicating good reliability in interpretation of 'radiological constipation'.

\section{Radiological characteristics of study population}

Table 1 summarises the radiological characteristics of the study population $(n=128)$. Seventy-four per cent (94) of subjects had megacolon of at least one segment of the lower bowel. Forty-eight per cent (45) of the individuals with megacolon had colonic dilatation in the absence of constipation, implying chronicity of their bowel condition. The prevalence of dilatation of the right side of the colon $(62.5 \%)$ was greater than that in the descending or sigmoid colon $(46.1 \%)$. Megarectum was highly prevalent, affecting 79\% of the study population. Small bowel dilatation was surprisingly common, being evident on $39 \%$ of abdominal Xrays.

Over half of the total study population (56\%) had radiological constipation, with distribution of severe stool retention tending to be slightly more prevalent in the right colon than in the left colon. Severe stool retention was least prevalent in the rectum, possibly because of administration of suppositories and enemas shortly before the AXR in some cases. Radiological constipation was present in 52\% (49) of patients with megacolon, and univariate analysis suggested that patients with megacolon were significantly more likely to be radiologically constipated (relative risk $=1.26$ $(95 \%$ CI $1.0-1.5))$, as compared to those without colonic dilatation.

\section{Patient characteristics}

Table 2 summarises patient characteristics for the study population. The mean age of all 128 subjects was $57 \pm 15$ years, and $97 \%$ of participants were male. The predominance of men reflects the demographic representation of the Veterans Administration population, and also the higher incidence of SCI in men. ${ }^{10}$ The average number of years since injury was $20 \pm 13$. Fifty-four per cent of individuals were quadraplegic, and $52 \%$ of subjects were classified as Frankel grade A (no motor or sensory function below the level of SCI). Almost half of the study population were taking six or more prescribed medications.

Fifty-eight per cent of subjects were prescribed use of at least one laxative, suppository or enema per week. On interview, 53\% reported at least once weekly use, with $13 \%$ taking an oral stimulant laxative (senna or bisacodyl), 20\% taking docusate sodium (a faecal softener), $11 \%$ magnesium hydroxide (a saline laxative), $7 \%$ bulk laxatives (methylcellulose or psyllium), and 1\% hyperosmolar laxatives (lactulose or sorbitol). Thirty per cent of patients used bisacodyl suppositories, and 4\% enemas.

\section{Univariate associations with megacolon}

Table 2 shows clinical and pharmacological associations with megacolon, prior to adjustment for possible confounding factors. Characteristics placing subjects at greater risk of megacolon were age over 50 years, SCI more than 10 years previously, a history of urinary outlet surgery, at least once weekly use of laxatives, use of anticholinergic drugs, and use of calcium-containing antacids.

Table 1 Radiological characteristics of study population

\begin{tabular}{ll}
\hline Radiological characteristic & $\%$ subjects $(\mathrm{n}=128)$ \\
\hline Megacolon (maximum diameter of any colonic segment $>6 \mathrm{cms}):$ & $73.5(94)$ \\
Dilatation ascending colon & $62.5(80)$ \\
Dilatation transverse colon & $62.5(80)$ \\
Dilatation descending and/or sigmoid colon & $46.1(59)$ \\
Megarectum (rectal diameter $\geqslant 4 \mathrm{cms})$ & $78.9(101)$ \\
Dialatation small bowel ( $\geqslant 3 \mathrm{cms})$ & $39.1(50)$ \\
Radiological constipation (total score $>8): *$ & $55.5(71)$ \\
Severe faecal retention ascending colon & $61.7(79)$ \\
Severe faecal retention transverse colon & $56.3(72)$ \\
Severe faecal retention descending and/or sigmoid colon & $57.8(74)$ \\
Severe faecal retention rectum & $46.9(60)$ \\
Megacolon without faecal retention & $35.2(45)$ \\
\hline
\end{tabular}

*Significant univariate association with megacolon (relative risk 1.26, 95\% CI 1.0-1.5) 
Table 2 Patient characteristics with univariate associations for megacolon

\begin{tabular}{|c|c|c|c|c|}
\hline Characteristics & $\begin{array}{c}\text { Total population } \\
\mathrm{n}=128 \\
\%(\mathrm{n})\end{array}$ & $\begin{array}{c}\text { Megacolon } \\
\mathrm{n}=94 \\
\%(\mathrm{n})\end{array}$ & $\begin{array}{c}\text { No megacolon } \\
\mathrm{n}=34 \\
\%(\mathrm{n})\end{array}$ & $\begin{array}{l}\text { Relative risk } \\
(95 \% \mathrm{CI})\end{array}$ \\
\hline \multicolumn{5}{|l|}{ Age } \\
\hline$\leqslant 50$ years & $30.5(39)$ & $24.5(23)$ & $47.1(16)$ & \\
\hline$>50$ years* & $69.5(89)$ & $75.5(71)$ & $52.9(18)$ & $1.36(1.1-1.8)$ \\
\hline Sex ( $\%$ male $)$ & $96.9(124)$ & $97.9(92)$ & $94.1(32)$ & $\mathrm{N} / \mathrm{S}$ \\
\hline Reason for admission & & & & $\mathrm{N} / \mathrm{S}$ \\
\hline Routine check-up & $73.4(94)$ & $72.0(67)$ & $79.4(27)$ & \\
\hline Acute medical/surgical & $13.3(17)$ & $15.1(14)$ & $8.8(3)$ & \\
\hline Long-term care & $13.3(17)$ & $12.9(12)$ & $11.8(4)$ & \\
\hline \multicolumn{5}{|l|}{ Time elapsed since injury } \\
\hline$\leqslant 10$ years & $25.8(33)$ & $21.3(20)$ & $38.2(13)$ & \\
\hline$>10$ years* & $74.2(95)$ & $78.7(74)$ & $61.8(21)$ & $1.29(1.0-1.7)$ \\
\hline \multicolumn{5}{|l|}{ Level of injury } \\
\hline Cervical & $53.8(70)$ & $56.4(53)$ & $50.0(17)$ & \\
\hline Thoracic & $37.1(46)$ & $34.0(32)$ & $41.2(14)$ & \\
\hline Lumbar & $9.1(12)$ & $9.6(9)$ & $8.8(3)$ & \\
\hline \multicolumn{5}{|l|}{ Frankel grade } \\
\hline A & $51.5(66)$ & $52.1(49)$ & $50.0(17)$ & \\
\hline $\mathrm{B}$ & $16.7(21)$ & $18.1(17)$ & $11.8(4)$ & \\
\hline $\mathrm{C}$ & $21.2(27)$ & $21.3(20)$ & $20.6(7)$ & \\
\hline $\mathrm{D}$ & $10.6(14)$ & $8.5(8)$ & $17.6(6)$ & \\
\hline Diabetes mellitus & $13.6(14)$ & $10.6(10)$ & $11.8(4)$ & $\mathrm{N} / \mathrm{S}$ \\
\hline Urinary outlet surgery & $37.1(48)$ & $42.6(40)$ & $23.5(8)$ & $1.24(1.0-1.5)$ \\
\hline $\begin{array}{l}\text { Six or more prescribed } \\
\text { medications }\end{array}$ & $47.7(61)$ & 50.0 & $41.2(14)$ & $\mathrm{N} / \mathrm{S}$ \\
\hline $\begin{array}{l}\text { One or more laxative dose } \\
\text { prescribed/week }\end{array}$ & $57.8(74)$ & $58.5(55)$ & $55.9(19)$ & $\mathrm{N} / \mathrm{S}$ \\
\hline $\begin{array}{l}\text { One or more laxative dose } \\
\text { taken/week }\end{array}$ & $53.1(68)$ & $57.5(54)$ & $41.2(14)$ & $1.32(1.0-1.8)$ \\
\hline Anticholinergic drugs & $19.5(25)$ & $23.4(22)$ & $8.8(3)$ & $1.25(1.0-1.5)$ \\
\hline Baclofen & $39.1(50)$ & $41.5(39)$ & $32.4(11)$ & $\mathrm{N} / \mathrm{S}$ \\
\hline Benzodiazepines & $43.0(55)$ & $43.6(41)$ & $41.2(14)$ & $\mathrm{N} / \mathrm{S}$ \\
\hline Narcotics & $11.7(15)$ & $8.6(11)$ & $11.8(4)$ & $\mathrm{N} / \mathrm{S}$ \\
\hline NSAID's/asprin & $15.6(20)$ & $17.0(16)$ & $11.8(4)$ & $\mathrm{N} / \mathrm{S}$ \\
\hline $\begin{array}{l}\text { Calcium-containing } \\
\text { antacids }\end{array}$ & $12.5(16)$ & $14.9(14)$ & $5.9(2)$ & $1.21(1.0-1.5)$ \\
\hline
\end{tabular}

*Significant univariate association with megacolon

Bowel-related symptoms and characteristics

Among the study population, 35\% reported spending more than $1 \mathrm{~h}$ on bowel emptying (Table 3). Twenty-three per cent had needed manual evacuation at least once during a 1-month period, in addition to usual bowel care. Of current bowel-related symptoms, 34\% reported abdominal pain, $43 \%$ abdominal distension, and $28 \%$ faecal incontinence occurring at least once a month, while $13 \%$ reported headaches or sweats relieved by bowel emptying. Bowel care was self-administered by $42 \%$ of subjects, and $29 \%$ reported regular use of digital stimulation. Thirty-three per cent of individuals felt that their bowel symptoms limited their usual activities, with $11 \%$ reporting a major negative impact. The only bowel-related character- istic associated with megacolon was bowel distension; patients with this symptom were 33\% more likely to have megacolon on AXR.

\section{Correlates of megacolon in multivariate analyses}

Table 4 shows that three of these correlates remained predictors of megacolon after simultaneous inclusion in a multivariate model. Patients who suffered SCI more than 10 years previously were almost four times more likely to have megacolon. An independent, if slightly weaker correlate (adjusted odds ratio (AOR) 2.8) was age over 50 years. Individuals taking laxatives at least once a week had a greater than threefold likelihood of megacolon. A subgroup analysis with multiple regression modelling was used to examine risk factors for the 45 
Table 3 Bowel-related symptoms and characteristics

\begin{tabular}{|c|c|c|c|}
\hline Bowel-related symptoms and characteristics & $\begin{array}{l}\text { Total population } \\
\mathrm{n}=128 \\
\%(\mathrm{n})\end{array}$ & $\begin{array}{c}\text { Megacolon } \\
\mathrm{n}=94 \\
\%(\mathrm{n})\end{array}$ & $\begin{array}{c}\text { No megacolon } \\
\mathrm{n}=34 \\
\%(\mathrm{n})\end{array}$ \\
\hline $\begin{array}{l}\text { Time spend on bowel evacuation } \\
<1 \mathrm{~h} \\
1-2 \mathrm{~h} \\
>2 \mathrm{~h}\end{array}$ & $\begin{array}{r}47.7(61) \\
25.8(33) \\
9.4(12)\end{array}$ & $\begin{array}{l}45.7(43) \\
26.6(25) \\
10.6(12)\end{array}$ & $\begin{aligned} 52.9(18) \\
23.9(8) \\
5.9(2)\end{aligned}$ \\
\hline $\begin{array}{l}\text { Additional manual evacuation required } / \mathrm{mo} \\
\text { None } \\
\text { At least once }\end{array}$ & $\begin{array}{l}57.8(74) \\
22.7(29)\end{array}$ & $\begin{array}{l}55.3(52) \\
24.5(23)\end{array}$ & $\begin{array}{l}54.7(22) \\
17.6(6)\end{array}$ \\
\hline $\begin{array}{l}\text { Abdominal pain/month } \\
\text { None } \\
\text { At least once }\end{array}$ & $\begin{array}{l}48.4(62) \\
33.6(43)\end{array}$ & $\begin{array}{l}47.9(45) \\
34.4(32)\end{array}$ & $\begin{array}{l}50.5(17) \\
32.4(11)\end{array}$ \\
\hline $\begin{array}{l}\text { Abdominal distension/month* } \\
\text { None } \\
\text { At least once* }\end{array}$ & $\begin{array}{l}30.5(39) \\
43.0(55)\end{array}$ & $\begin{array}{l}24.5(23) \\
45.7(43)\end{array}$ & $\begin{array}{l}47.1(16) \\
35.3(12)\end{array}$ \\
\hline Headache relieved by evacuation & $13.3(17)$ & $12.7(12)$ & $14.7(5)$ \\
\hline $\begin{array}{l}\text { Faecal incontinence/month } \\
\text { None } \\
\text { At least once } \\
\text { Evacuation induced by meal }\end{array}$ & $\begin{array}{l}53.1(68) \\
28.1(36) \\
15.6(20)\end{array}$ & $\begin{array}{l}54.3(51) \\
27.7(26) \\
14.9(14)\end{array}$ & $\begin{array}{l}50.0(17) \\
29.4(10) \\
17.6(6)\end{array}$ \\
\hline $\begin{array}{l}\text { Who does bowel care? } \\
\text { Self } \\
\text { Family member } \\
\text { Nurse/attendant } \\
\text { Digital stimulation }\end{array}$ & $\begin{array}{l}41.4(53) \\
10.2(13) \\
31.3(40) \\
28.9(37)\end{array}$ & $\begin{array}{l}39.4(37) \\
11.7(11) \\
31.9(30) \\
26.6(25)\end{array}$ & $\begin{aligned} 47.1 & (16) \\
5.9 & (2) \\
29.4 & (10) \\
35.3 & (12)\end{aligned}$ \\
\hline $\begin{array}{l}\text { How much do bowel symptons limit user ac } \\
\text { Not at all } \\
\text { Some } \\
\text { A lot }\end{array}$ & $\begin{array}{l}39.1(50) \\
21.9(28) \\
10.9(14)\end{array}$ & $\begin{array}{l}41.5(39) \\
29.8(15) \\
10.6(10)\end{array}$ & $\begin{array}{l}32.4(11) \\
38.2(13) \\
11.8(4)\end{array}$ \\
\hline
\end{tabular}

*Significant univariate association with megacolon $(\mathrm{RR}=1.33,95 \%$ CI $(1.0-1.4))$

Table 4 Factors independently associated with megacolon

\begin{tabular}{lc}
\hline Characteristic & Adjusted odds ratio with 95\% CI \\
\hline More than 10 years elapsed since injury & $3.71(1.2-11.6)$ \\
Age $>50$ years & $2.84(1.0-8.3)$ \\
$\geqslant 4$ laxative doses taken per month & $3.19(1.1-9.1)$ \\
\hline
\end{tabular}

individuals who had chronic megacolon (persistent colonic dilatation in the absence of constipation). The same correlates were seen but with even stronger predictive values, though the smaller subject number is reflected in the wider confidence intervals: $\mathrm{SCI}>10$ years (AOR 4.4, 1.0-21.2), age $>50$ years (AOR 4.3, 1.117.1), and weekly laxative use (AOR 5.0, 1.3-19.6).

\section{Discussion}

Three-quarters of our study population of individuals with chronic SCI had megacolon on routine AXR, $79 \%$ had megarectum, and a surprising 39\% had dilatation of the small bowel. Time elapsed since injury was the strongest predictor of megacolon, while advancing age also proved a significant independent risk factor. Patients with megacolon were more likely to be using greater amounts of laxatives. In the unadjusted analysis, patients with megacolon suffered more from constipation and abdominal distension, and were more likely to be taking certain constipating medications. To the best of our knowledge, no previous study has described the correlates of megacolon in chronic SCI.

Prevalence of megacolon in SCI

Our findings suggest that the majority of individuals with SCI will acquire radiological features of megacolon. Half of our patients with megacolon had bowel 
distension in the balance of stool retention suggesting a persistent condition of lower bowel dysfunction. There is no available comparative data on prevalence of megacolon in chronic SCI. The high prevalence found in the present study may be influenced by the age of study subjects (mean $57 \pm 15$ years), and the average number of years since injury $(20 \pm 13)$. However, this demographic and clinical profile is increasingly characteristic of patients with chronic SCI as improved medical care leads to more individuals surviving into old age.

Gut pathophysiology predisposing to megacolon in SCI The likely pathophysiological pathways leading to acquired megacolon depend on the level of SCI. ${ }^{5,11}$ Lumbosacral trauma interrupts parasympathetic outflow to the gut, rendering the descending colon and rectosigmoid immobile and excessively compliant, tending toward development of megacolon and rectum early on after injury. ${ }^{12}$ Megacolon may occur following lumbar spinal surgery with older patients being particularly susceptible, ${ }^{13}$ and with lumbar spinal stenosis. ${ }^{14}$ Cervicothoracic injury interrupts cortical inhibitory pathways creating excessive sympathetic stimulation and increased smooth muscle tone throughout the colon, ${ }^{15,16}$ and anorectal dyssynergia, where the internal anal sphincter is unable to relax in response to contraction of the rectum. ${ }^{6,15,16}$ The result is chronic faecal impaction which over time overcomes hypertonicity and leads to decompensation of colorectal smooth muscle and eventual megacolon, ${ }^{2,15-17}$ just as chronic ouflow obstruction in SCI leads to an excessively compliant bladder as a result of progressive decompensation of the detrusor muscle. ${ }^{4,15,18}$ Further work is still needed to define the pathophysiological basis of megacolon in chronic SCI, and to clarify the impact of time elapsed since injury on lower gut physiology.

Thirty-nine per cent of our subjects had small bowel dilatation on routine radiography, even though gut transit studies have shown that small bowel motility is unaffected by SCI. ${ }^{4,15}$ Small bowel distension may therefore largely result from stool retention in the ascending colon causing back pressure on the ileocaecal valve. ${ }^{4,15}$ Our finding that the ascending colon was the segment most prone to constipation would tend to support this. The clinical implications of chronic small bowel dilatation in SCI are as yet unexplored.

\section{Relationship of post-injury years with megacolon}

Our results showed that a post-injury period of 10 years or more placed patients at an almost fourfold greater risk of having megacolon, supporting the hypothesis of this being a condition acquired over time. Acquired megacolon may feasibly be a primary cause of worsening GI symptoms in longstanding SCI; difficulty with evacuation, abdominal pain, and faecal incontinence are increasingly common beyond the first 5 years post-injury, ${ }^{2,19}$ and each decade post-injury has been shown to more than double the odds of clinical constipation. $^{3}$ Our findings confirm that patients beyond the first decade post-injury are at high risk of having megacolon, and should be regularly assessed for symptoms and complications of constipation.

\section{Relationship of ageing with megacolon}

We examined time elapsed since injury and age as two discrete variables, and found that age over 50 years presented an almost threefold increase in risk for the presence of megacolon. Age does affect recovery of bowel function following acute SCI; patients beyond 50 years are significantly less likely to achieve unassisted bowel evacuation by the time of hospital discharge, as compared with younger individuals. $^{20}$ In healthy people, ageing alone does not alter the physiology of the colon, ${ }^{21-23}$ but clinical factors common to both elderly and disabled populations such as reduced mobility, neurological disability and polypharmacy can impact lower gut motility. $^{24-26}$ Gastrointestinal disorders other than constipation, which are also normally associated with older age, such as hiatus hernia, gastro-oesophageal reflux, and diverticulosis, have been observed to occur at a much higher prevalence in the 3rd and 4 th decade in $\mathrm{SCI}^{5}$ raising the question 'Does chronic SCI accelerate the onset of age-related diseases throughout the GI tract'?

Another potential factor is that older people may be less effective in self-administrating bowel care, bearing in mind that $40 \%$ of our study group undertook their own bowel programme. Age beyond 50 years in chronic SCI is associated with greater fatigue, reduced physical activity and increased dependency, ${ }^{19,27}$ all of which could impact the effectiveness of self-administered bowel care. A detailed history of current bowel care, and any problems with evacuation should be regularly elicited from older SCI patients to avoid a downward spiral of worsening bowel dysfunction.

\section{Association between megacolon and constipation}

The prevalence of radiological constipation has not been previously documented in SCI patients. We found that over half the study population had marked constipation on the AXR, with stool retention tending to be more severe in the right colon. Stool retention was least apparent in the rectosigmoid, probably because of regularly administered bowel care. ${ }^{15}$ Patients with megacolon were more likely to have severe constipation on AXR; although this study is unable to define whether this finding is cause or effect, it does imply that there is a need for more effective bowel care in this population. Missing of scheduled bowel programmes has in particular been associated with less effective clearance. ${ }^{1,28,29}$ Intermittent patient education on regular evacuation, correct techniques of 
digital stimulation and suppository insertion, ${ }^{1,30,31}$ and dietary advice (including fibre intake) ${ }^{28,29,32}$ may well promote improved bowel care over the long-term.

\section{Association between megacolon and GI symptoms}

Although our subjects reported a high prevalence of bowel-related symptoms (comparable to other studies), ${ }^{1,20,30,31}$ only abdominal distension correlated with megacolon. Recurrent abdominal distension is strongly associated with severe constipation in chronic SCI, ${ }^{1,2,30}$ and should be considered a primary clinical indicator of colonic dysfunction in this population.

\section{Laxative use and megacolon}

We observed that patients with megacolon required more frequent administration of laxatives to accomplish catharsis, probably due in part to the impaired contractility of the lower bowel. Another factor may be that current patterns of laxative use are ineffective in these patients. With so few published clinical trials of laxatives in SCI patients, prescribing by physicians tends to be somewhat empirical. Docusate sodium, the most commonly used agent in the SCI population in the $\mathrm{USA}^{29}$ is a stool softener with little impact on gut motility in non-injured individuals ${ }^{26,33}$ and is therefore unlikely to have any significant laxative effect in people with neuropathic bowel. Likewise, the contractile response to stimulant laxatives (the second most commonly used class in this study) would be expected to diminish as megacolon develops. Randomised clinical trials are needed to evaluate the efficacy of stimulant agents such as senna and danthron in SCI patients, with stratified analyses to examine the subgroup with megacolon. The little used groups of hyperosmolar and bulk laxatives also merit further examination in SCI patients, as the former effectively treat faecal impactions in non-injured individuals with colonic dysfunction, ${ }^{34}$ and the latter are useful in the elderly. ${ }^{25}$ Even the minimal administration of enemas in this study may represent underuse, as evidence suggests that regular administration of $500 \mathrm{ml}$ volume tap water enemas is beneficial in reducing evacuation time and episodes of overflow incontinence in SCI patients. ${ }^{35}$ Newer treatments tended to be overlooked by prescribers in this study; while almost a third of patients regularly used conventional bisacodyl suppositories, few were prescribed the most effective polyethylene glycol based bisacodyl suppositories. ${ }^{36,37}$ Virtually no patients were taking cisapride (a prokinetic agent mediated by increased release of acetyl choline in the myenteric plexus), which has been shown to have good laxative effect on the neuropathic bowel in SCI. ${ }^{38,39}$ Clearly there is need for further research in effective treatment of constipation in SCI patients with and without megacolon, but meanwhile, physicians should regularly review the clinical benefit of bowel agents used by their patients.

\section{Univariate associations with megacolon}

The univariate association observed between use of antimuscarinic medications (antidepressants, tranquillisers, bladder drugs) and megacolon may be explained by the inhibitory effect on acetylcholine receptors sites in the smooth muscle of the gut. Regular use of these drugs among SCI patients has been linked to more severe constipation symptoms, ${ }^{30}$ so wherever possible, use of drugs with potent anticholinergic properties should be avoided in this population. Likewise, our study findings implied that use of calcium-containing antacids increases the risk of megacolon (calcium having a direct action on smooth muscle); aluminium-containing alternatives should preferentially be prescribed.

The univariate relationship between previous urinary outlet surgery and megacolon is understandable considering that the bladder and rectum are jointly innervated, and respond similarly to adrenergic and cholinergic stimuli. Clinically, prior sphincterotomy has been associated with difficulties in evacuation. ${ }^{12}$ Conversely, rectal distension (observed during urodynamic studies) reduces bladder compliance, and increases dyssynergia between the detrusor muscle and external urethral sphincter. ${ }^{40}$ The impact of chronic megacolon, as observed in $79 \%$ of our patients, on bladder function is unclear but merits further examination.

\section{Potential complications of megacolon in SCI}

The high prevalence of megacolon is important because of the significant potential complications associated with the diagnosis. The most common surgical complication is colonic volvulus, which has a reported incidence of $2.6 \%$ (observed in SCI patients hospitalised for other reasons). ${ }^{41}$ The presence of megacolon significantly increases the recurrence rate of sigmoid volvulus following sigmoid colectomy, and it is recommended that such individuals undergo subtotal colectomy for effective surgical treatment. ${ }^{42}$ Medical complications of megacolon include faecal impaction (the commonest GI complication in chronic SCI), autonomic dysreflexia, 1,11,43 dyspnoea from diaphragmatic splinting, ${ }^{44}$ weight loss and chronic malnutrition. $^{45,46}$ Where such complications result in recurrent hospitalisations, colostomy may be an alternative remedy. ${ }^{28,45}$ Not to be overlooked are the psychosocial implications of neurogenic bowel including missing work days, feelings of anxiety, and loss of self-confidence. ${ }^{28,47,48}$ People with SCI are living longer with their disability, and there is an every-growing need to assess the impact of chronic conditions such as megacolon on patients' lives.

\section{Usefulness of the AXR in SCI patients}

The AXR proved a useful tool in identifying megacolon in this study, and in evaluating the extent and distribution of faecal retention throughout the colon. The 4-line method is a useful guide to AXR 
interpretation for clinicians, though correct identification of colonic dilatation by segment may be hampered by the presence of a low-lying transverse colon or redundant sigmoid loops. ${ }^{49}$ In this study however, the radiologist showed a very good reliability score in AXR interpretation. The plain AXR can accurately diagnose faecal impaction, and caecal and sigmoid volvulus (because of the distinctive gas patterns), $5,17,41$ both common complications in patients with megacolon. AXR's should be considered in SCI management where patients are symptomatic or report changes in bowel care.

\section{Study limitations}

Although we did attempt to control for the presence of potential confounding factors in this study, certain variables such as diet (in particular fluid and fibre intake) were not examined. A long-term prospective study of SCI patients in which such variables amongst others are collected is the most accurate way of examining risk factors for the development of megacolon. Our subjects were all hospitalised which may produce a bias toward a 'sicker' subgroup of the SCI population. However, $73 \%$ of our study population were admitted for a routine annual check-up, being otherwise healthy. We also adjusted for the reason for hospitalisation in the multivariate analysis of correlates of megacolon.

\section{Conclusions}

Megacolon is a highly prevalent disorder in individuals with chronic spinal cord injury. Our findings suggest that the presence of megacolon may be predicted in older individuals, and in those who are more than 10 years post-SCI. We also found that clinical constipation was frequently present in individuals with megacolon, despite their significantly greater use of laxatives. Routine monitoring of GI problems, focusing on increasing laxative use, difficulties with evacuation and recurrent abdominal distension, should be part of the ongoing care of patients ageing with SCI. The AXR will give useful information about colonic dilatation, dysmotility and stool retention. Rigorous clinical trials are needed to evaluate effective treatment approaches to constipation in SCI patients with and without megacolon, and a longitudinal study is required to examine whether effective bowel clearance may delay or even prevent the development of megacolon in chronic SCI.

\section{Acknowledgements}

The authors thank Dr $\mathbf{J}$ Gilliam for interpretation of abdominal radiographs, Susanne Brown and Laura Grande for assistance with data collection, and Professor Cameron $\mathrm{G}$ Swift for valuable editorial comment. We also thank the patients and staff of the West Roxbury/Brockton Veterans Administration Medical Centre SCI Service.

\section{References}

1 Harari D et al. Constipation-related symptoms and bowel program concerning individuals with spinal cord injury. Spinal Cord 1997; 35: $394-401$.

2 Stone JM, Nino-Murcia M, Wolfe V, Perkash I. Chronic gastrointestinal problems in spinal cord injury patients; a prospective analysis. Am J Gastroenterol 1990; 85: 1114-1119.

3 Menter $\mathrm{R}$ et al. Bowel management outcomes in individuals with long-term spinal cord injuries. Spinal Cord 1997; 35: 608-612.

4 Cosman BC, Stone JM, Perkash I. Gastrointestinal complications of chronic spinal cord injury. J Am Paraplegia Soc 1991; 14: $175-181$

5 Gore RM, Mintzer RA, Calenoff L. Gastrointestinal complications of spinal cord injury. Spine 1981; 6: $538-544$.

6 Menardo G et al. Large- bowel transit in paraplegic patients. Dis Colon Rectum 1987; 30: 924-928.

7 Frankel HL et al. The value of postural reduction in the initial management of closed injuries of the spine with paraplegia and tetraplegia. Paraplegia 1969; 7: 179-192.

8 Starrveld JS et al. The plain abdominal radiograph in the assessment of constipation. Z Gastroenterol 1990; 28: 335-382.

9 Burhemme HJ. Colon. In: Margulis AR (ed). Practical alimentary tract radiology. Mosby Year Book: Boston, 1993, pp. 251.

10 Bracken B et al. Incidence of acute traumatized hospitalized spinal cord injury in the United States, 1970-1977. Am J Epidemiol 1981; 113: 615-622.

11 Banwell JG, Creasy GH, Aggarwal AM, Mortimer JT. Management of the neurogenic bowel in patients with spinal cord injury. Urologic Clin North Am 1993; 20: 517 - 526.

12 Devroed C et al. Traumatic constipation. Gastroenterol 1979; 77: $1258-1267$.

13 Feldman RA, Karl RC. Diagnosis and treatment of Ogilvie's syndrome after lumbar spinal surgery. J Neurosurg 1992; 76: $1012-1016$.

14 Gattuso JM, Kamm MA. Clinical features of megarectum and idiopathic megacolon. Gut 1997; 41: 93-99.

15 Nino-Murcia M, Stone JM, Chang PJ, Perkash I. Colonic transit in spinal cord-injured patients. Invest Radiol 1990; 25: 109-112.

16 Glick ME et al. Colonic dysfunction in patients with thoracic spinal cord injury. Gastroenterol 1984; 86: 287-294.

17 Mezwa DG, Feczko PJ, Bosanko C. Radiologic evaluation of constipation and anorectal disorders. Radiol Clin North Am 1993; 31: $1375-1393$.

18 Cardenas DD, Mayo ME, Turner LR. Lower urinary changes over time in suprasacral spinal cord injury. Paraplegia 1995; 33: $326-329$.

19 Pentland W, McColl MA, Rosenthal C. The effect of aging and duration of disability on long term health outcomes following spinal cord injury. Paraplegia 1995; 33: 367-373.

20 Penrod LE, Hegde SK, Ditunno JF. Age effect on prognosis for functional recovery in acute, traumatic central cord syndrome. Arch Phys Med Rehabil 1990; 71: 963-968.

21 Melkersson $\mathrm{M}$ et al. Intestinal transit time in constipated and non-constipated geriatric patients. Scand J Gastroenterol 1983; 18: $593-597$

22 Loening-Baucke V, Anuras S. Sigmoidal and rectal motility in healthy elderly. J Am Geriatr Soc 1984; 32: 887-891.

23 Harari $\mathrm{D}$ et al. Bowel habits in relation to age and gender: Findings from the National Health Interview Survey and clinical implications. Arch Int Med 1996; 156: $315-320$.

24 Sonnenberg A, Tsou VT, Muller AD. The 'institutional colon': a frequent colonic dysmotility in psychiatric and neurologic disease. Am J Gastroenterol 1994; 89: $62-66$.

25 Harari D, Gurwitz JH, Minaker KL. Constipation in the elderly. J Am Geriatr Soc 1993; 41: 1130 - 1140.

26 Harari D et al. Correlates of regular laxative use in frail elderly persons. Am J Med 1995; 99: 513-518.

27 Menter RR et al. Impairment, disability, handicap and medical expenses of persons aging with spinal cord injury. Paraplegia 1991; 29: $613-619$. 
28 Matthews Kirk P et al. Long-term follow-up of bowel management after spinal cord injury. SCI Nursing 1997; 14: 56-63.

29 Kirshblum SC, Gulati M, O'Connor KC, Voorman SJ. Bowel care practices in chronic spinal cord injury patients. Arch Phys Med Rehabil 1998; 79: 20-23.

30 De Looze D et al. Constipation and other chronic gastrointestinal problems in spinal cord injury patients. Spinal Cord 1998; 36: $63-66$.

$31 \mathrm{Krogh} \mathrm{K}$ et al. Colorectal function in patients with spinal cord lesions. Dis Colon Rectum 1997; 40: $1233-1239$.

32 Badiali D et al. Sequential treatment of chronic constipation in paraplegic patients. Spinal Cord 1998; 35: 116-120.

33 Chapman RW et al. Effect of oral dioctyl sodium sulfosuccinate on intake-output studies of human small and large intestine. Gastroenterology 1985; 89: 489-493.

34 Puxty JA, Fox RA. Golytely: a new approach to faecal impaction in old age. Age Ageing 1986; 15: $182-184$.

35 Cornell $\mathrm{S}$ et al. Comparison of three bowel management programs. Nursing Res 1973; 22: $321-327$.

36 Steins S. Reduction in bowel program duration with polyethylene glycol based bisacodyl suppositories. Arch Phys Med Rehabil 1995; 76: $674-677$.

37 Frisbie JH. Improved bowel care with a polyethylene glycol based bisacodyl suppository. J Spinal Cord Med 1997; 20: 227 229.

38 Longo WE et al. Cisapride for constipation in spinal cord injured patients: A preliminary report. J Spinal Cord Med 1995; 18: 240 244.

39 Geders JM, Gaing A, Bauman WA, Korsten MA. The effect of cisapride on segmental colonic transit time in patients with spinal cord injury. Am J Gastroenterol 1995; 90: 285-289.
40 Carone R, Petrillo M, Vercelli D, Bertapelle P. Mutual influence between vesicourethral and anorectal function in spinal cord patients. Paraplegia 1995; 33: 34-35.

41 Fenton-Lee D, Yeo BW, Jones RH, Engel S. Colonic volvulus in the spinal cord injured patient. Paraplegia 1993; 31: 393-397.

42 Morrissey TB, Deitch EA. Recurrence of sigmoid volvulus after surgical intervention. Am Surgeon 1994; 60: 329-331.

43 Krassioukov AV, Weaver LC. Episodic hypertension due to autonomic dysreflexia in acute and chronic spinal cord-injured rates. Am J Physiol 1995; 268: $\mathrm{H} 2077-\mathrm{H} 2083$.

44 Nava S, Schiavoni PG. Hemidiaphragm dysfunction due to megacolon: functional recovery after colectomy. Monaldi Arch Chest Dis 1995; 50: $18-20$.

45 Stone JM, Wolfe VA, Nino-Murcia M, Perkash I. Colostomy as treatment for complications of spinal cord injury. Arch Phys Med Rehabil 1990; 71: 514-518.

46 Vieira MJ et al. Preoperative assessment in cases of adult megacolon suffering from moderate malnutrition. Nutrition 1996; 12: $491-495$

47 Levi R, Hulting C, Nash MS, Seiger A. The Stockholm spinal cord injury study: Medical problems in a regional SCI population. Paraplegia 1995; 33: $308-315$.

48 Hanson RW, Franklin MR. Sexual loss in relation to other functional losses for spinal cord injured males. Arch Phys Med Rehabil 1976; 57: 291-293.

49 Baker SR. The abdominal plain film. What will be its role in the future? Radiol Clin North Am 1993; 31: 1335 - 1344. 